\title{
Evaluation of degradation kinetics for abamectin in formulations using a stability indicating method
}

\author{
ATUL AWASTHI ${ }^{1}$ \\ MAJID RAZZAK ${ }^{2}$ \\ RAIDA AL-KASSAS ${ }^{1}$ \\ JOANNE HARVEY 3 \\ SANJAY GARG ${ }^{1,4, *}$ \\ 1 School of Pharmacy, The University of \\ Auckland, New Zealand \\ ${ }^{2}$ Ancare Scientific Ltd, Auckland \\ New Zealand \\ ${ }^{3}$ School of Chemical and Physical Sciences \\ Victoria University of Wellington \\ New Zealand \\ 4 School of Pharmacy and Medical Sciences \\ University of South Australia, Australia
}

\begin{abstract}
The aim of this study was to evaluate stability characteristics and kinetics behavior of abamectin (ABM) as a $1 \%$ $(\mathrm{m} / \mathrm{V})$ topical veterinary solution. During the study, samples stressed at 55 and $70{ }^{\circ} \mathrm{C}$ were regularly analyzed for several parameters over 8 weeks on a chromatographic (HPLC) system, using a Prodigy C18, $250 \times 4.6 \mathrm{~mm}, 5-\mu \mathrm{m}$, column eluting with $15: 34: 51(\mathrm{~V} / \mathrm{V} / \mathrm{V})$ water/methanol/ acetonitrile as mobile phase. The HPLC method was validated for precision, accuracy, linearity and specificity, and was found to be stability indicating. The results showed that degradation of ABM followed first-order kinetics and data on loss in $k_{\mathrm{obs}}\left(\mathrm{s}^{-1}\right)$ and half life $\left(t_{1 / 2}\right.$, days) demonstrated ABM showing the maximum stability in glycerol formal. The degradation behavior of ABM varies from solvent to solvent. The effect of added alkali on $\mathrm{pH}$ change and loss of ABM was studied and found to be unique for all solvents and very distinct from typical hydrolysis degradation. The present study may serve as a platform to design and develop topical non-aqueous solutions of ABM for veterinary use given no such comprehensive efforts have been published to date on the stability profile of $\mathrm{ABM}$ in non-aqueous solvents.
\end{abstract}

Keywords: abamectin, stability, kinetics, degradation, solvent reactivity

Abamectin $(\mathrm{ABM})$, a mixture of avermectin $\mathrm{B} 1_{\mathrm{a}}$ and $\mathrm{B} 1_{\mathrm{b}}$ homologs, is widely used as an anthelmintic and antiparasitic agent for animals as well as humans (1-3). Avermectins (AVMs) are closely related 16-membered macrocyclic lactone compounds (see Fig. 1), derived from the soil microorganism Streptomyces avermitilis $(4,5)$.

$\mathrm{ABM}$ and other avermectin derivatives are known to be unstable under normal conditions of preparation, use and storage (6). It is therefore often recommended that AVMs be refrigerated, protected from moisture, kept away from light, their exposure to acidic

\footnotetext{
* Correspondence; e-mail: sanjay.garg@unisa.edu.au
} 


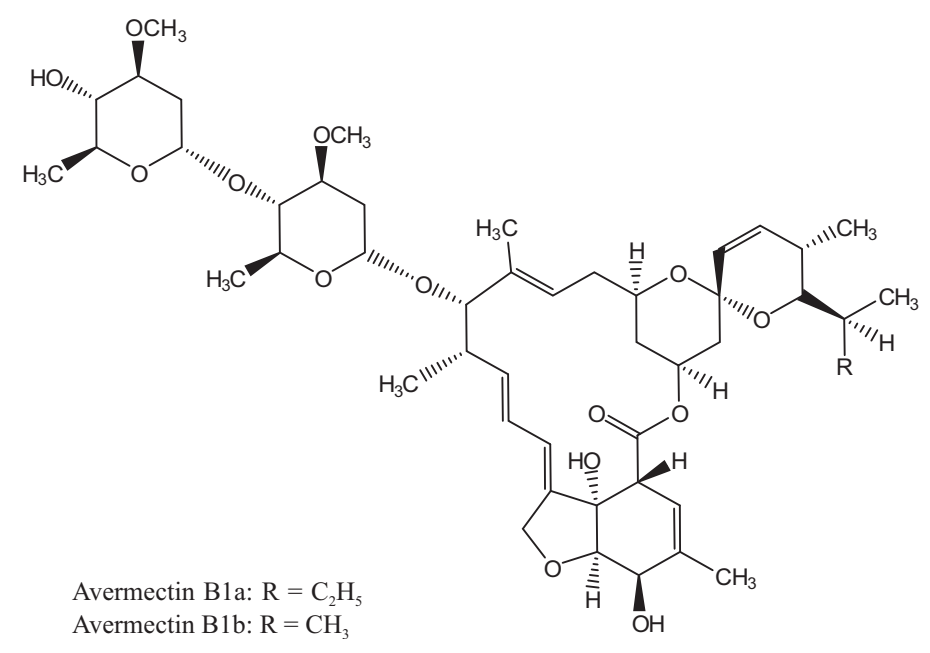

Fig. 1. Chemical structure of abamectin (avermectin B1a and B1b).

or alkaline conditions be limited and that the formulations contain a small amount of antioxidant to avoid auto-oxidation under atmospheric conditions (7). The unpredictable stability of ABM presents a challenge in developing it as a stable veterinary pharmaceutical product with a commercially viable shelf life under ambient storage conditions.

The stability of AVMs has been found to be significantly affected by acidic and alkaline media (8). Their exposure to mild acidic conditions leads to glycolysis, resulting in monosaccharide and aglycone derivatives (9). In contrast, alkaline hydrolysis results in epimerization to stereoisomer and regioisomer (2-epi- and $\Delta 2,3$-AVM) (10-12). There are also reports describing oxidation of the oxahydrindene unit as well as photodegradation, resulting in the 8,9-Z isomer of ABM molecule (13-15). These degradation products (DPs) such as monosaccharide, aglycone, 2-epi-, and $\Delta 2,3-$, etc., are known to lack the necessary anthelmintic actions of AVM (16).

There are limited publications that evaluate the physicochemical stability of ABM in formulations, in which significant interactions are expected from the excipients and vehicle in the sample matrix. Furthermore, there is an apparent lack of published information detailing the effect of solvents suitable for topical delivery on the stability of avermectins. It is well known that solvents, given their unique physicochemical properties such as the dipole moment, hydrogen bonding, Lewis acidity and Lewis alkalinity, can compromise the chemical stability of soluble drug compounds (17). Nevertheless, almost all published stability studies of ABM were mainly focused on aqueous medium and so far there is no information on the effect of non-aqueous solvents on ABM stability, in particular kinetic behavior under the influence of heat and when the medium is exposed to alkaline conditions.

The present study is therefore aimed at evaluating the stability and kinetic behavior of ABM in selected solvents commonly used in topical delivery systems. In addition, physicochemical changes induced by heat and apparent alkalinity will be thoroughly investigated and rates of degradation will be compared to indicate compositions showing 
better as well as poor stabilities. Since this information is first of its kind, the data on solvents can be used to develop stable pour-on preparations by choosing the right solvent or mixture of solvents.

\section{EXPERIMENTAL}

\section{Materials}

ABM (Zhejiang Hisun Pharmaceutical Co. Ltd., China) and solvents such as N-methylpyrrolidone (NMP) (Lyon Dell, Singapore), diethyleneglycol monobutylether (DGBE) (DOW, Malaysia), glycerol formal (47-67 \% 5-hydroxy-1,3-dioxane- and 33-53 \% 4-hydroxymethyl-1,3-dioxolane, GF) (Lambiotte, Belgium), dimethyl formamide (DMF) (Ajax, New Zealand) and ethyl lactate (EL) (Masashino, Japan), were used in the study. HPLC grade methanol $(\mathrm{MeOH})$ and acetonitrile $(\mathrm{ACN})$ were purchased from Merck (Germany). All other analytical reagent grade chemicals were purchased from Ajax Fine Chem (New Zealand). Ultrapure water having conductivity $<0.5 \mu \mathrm{S} \mathrm{m} \mathrm{m}^{-1}$ was obtained from a Purelab Ultra water system (ELGA LabWater, UK).

\section{Instruments}

HPLC analysis of stability samples was performed using a Prominence HPLC system (Shimadzu, Japan) equipped with an on-line degasser (DGU-20A5), low-pressure quaternary pump (LC-20AT), auto-injector (SIL-20AC), thermostated column compartment (CTO-20AC) and photodiode array detector (SPD-M20A). For data acquisition and processing, LCsolution, version 6.7 (Shimadzu) software was used.

During the study, samples were stored at 70 and $55 \pm 1^{\circ} \mathrm{C}$ in fully calibrated Thermotec 2000 ovens (Contherm Scientific Ltd, New Zealand). The pH of solutions was measured using a Cyberscan $510 \mathrm{pH}$ meter (Eutech Instruments, Singapore). During the studies A grade low actinic glassware was used.

\section{HPLC method and validation}

Chromatographic separation was performed using a Prodigy ODS3, $250 \mathrm{~mm} \times 4.6 \mathrm{~mm}$ i.d., particle size $5 \mu \mathrm{m}$, column (Phenomenex Inc., USA). A mobile phase consisting of $\mathrm{H}_{2} \mathrm{O} /$ methanol/acetonitrile (15:34:51, $\left.V / V / V\right)$ was run at a flow rate of $1.0 \mathrm{~mL} \mathrm{~min}^{-1}$ from the column maintained at $40{ }^{\circ} \mathrm{C}$. Detection was performed at $256 \mathrm{~nm}$.

Standard and sample solutions were prepared in methanol at a concentration of $100 \mu \mathrm{g} \mathrm{mL}^{-1}$ of $\mathrm{ABM}$ and injection volume was $50 \mu \mathrm{L}$. The preparations were filtered through $0.22-\mu \mathrm{m}$ nylon filters and vials were protected from strong light.

The method was validated with respect to linearity, method precision (intra-day, inter-day and intermediate), accuracy, specificity and solution stability, using current international guidelines (18).

To establish linearity and range, a stock solution of ABM was serially diluted to yield solutions in the concentration range $50-150 \mu \mathrm{g} \mathrm{mL}-1$. The intra- and inter-day precision 
was established by analyzing six replicate preparations on different days. Accuracy was determined in triplicate having known ABM concentration $\left(50,100\right.$ and $\left.150 \mu \mathrm{g} \mathrm{mL} \mathrm{m}^{-1}\right)$, spiked with placebo (equivalent to typical formulation sample mass), for each target concentration level. The specificity test was carried out by performing a forced degradation study (acid, alkali, peroxide, light and thermal) of typical formulation samples and respective placebo preparations, and determining purity parameters using a diode array detector. The stability of standard and sample solution was evaluated for a minimum of 24 hours at room temperature.

\section{Apparent $p H$ measurement}

During the course of the study, the apparent $\mathrm{pH}$ of stress samples was recorded by adding $1 \mathrm{~mL}$ of $0.5 \mathrm{~mol} \mathrm{~L}^{-1}$ aqueous $\mathrm{KCl}$ to $99 \mathrm{~mL}$ of ABM preparation (19). Readings were noted after 1 minute of stabilization time using a calibrated $\mathrm{pH}$ meter having \pm 0.05 accuracy.

\section{Kinetics parameters}

First-order degradation rate constant $\left(k_{\mathrm{obs}}\right)$ was calculated from the slopes of logarithm plots of drug concentration vs. time in days according to $E q$. (1):

$$
\ln \left(\frac{c_{\mathrm{t}}}{c_{0}}\right)=-k_{\mathrm{obs}} t
$$

where $c_{0}$ is the initial concentration and $c_{\mathrm{t}}$ is the remaining concentration of $\mathrm{ABM}$ at time $t$.

The effect of heat on the stability of ABM was studied using the Arrhenius equation. The frequency factor $(A)$ was calculated using $E q$. (2) and activation energy $\left(E_{\mathrm{a}}\right)$ was calculated using Eq. (3):

$$
\log k=\log A-\frac{E_{\mathrm{a}}}{2.303 R T}
$$

where $k$ is the specific rate constant of the degradation reaction, $A$ is the Arrhenius factor or frequency factor, $R$ is the gas constant of $8.314 \mathrm{~J} \mathrm{~K}^{-1} \mathrm{~mol}^{-1}$ and $T$ is absolute temperature:

$$
\log \frac{k_{2}}{k_{1}}=\frac{E_{\mathrm{a}}}{2.303 R\left(\frac{T_{2}-T_{1}}{T_{2} T_{1}}\right)}
$$

where $k_{1}$ and $k_{2}$ are degradation rate constants at the two storage temperatures $T_{1}$ and $T_{2}$. 


\section{Preparation of stability samples}

One percent $(m / V)$ solutions of ABM in NMP, DGBE, GF, DMF and EL were prepared. ABM was accurately weighed after purity correction and dissolved in individual solvents to a set volume, using a lab stirrer plate, in a vessel under nitrogen flow. As a precautionary measure, exposure to heat, strong light and process time were controlled to avoid any possible process degradation. The samples were sealed in 20-mL amber glass ampoules and placed under the respective study conditions, away from strong light. Each of the above samples, was divided into 3 categories to store at 5,70 and $55^{\circ} \mathrm{C}$ (control/alkali spiked). The alkali spiking experiment involved addition of $0.05 \mathrm{~mol} \mathrm{~L}^{-1}$ $\mathrm{KOH}$ to achieve a $1 \%(V / V)$ alkali solution in the preparation. $0.05 \mathrm{~mol} \mathrm{~L}^{-1} \mathrm{KOH}$ solution was prepared in the solvents used for the study. Three ampoules of each representative sample type were withdrawn at predefined time intervals and analyzed immediately.

\section{RESULTS AND DISCUSSION}

\section{Method validation}

The linearity of detector response $\left(R^{2}\right)$ was 0.9994 for five different concentrations, ranging from 49.86 to $146.87 \mu \mathrm{g} \mathrm{mL}^{-1}$ (50-150\% of target concentration). All method precision RSDs for intra-day and inter-day assays were $\leq 1.0 \%$ and accuracies for 50,100 and $150 \%(n=3)$ levels were within an acceptable range of $98.0-102.0 \%$, having RSD for replicate preparations $<1.0 \%$. The specificity study result of ABM formulation samples showed that ABM was very sensitive to alkaline conditions. In addition, it also displayed loss under acid, light and oxidation conditions. However, these losses were less than those caused by alkali hydrolysis. The peak purity analysis (purity > 99 \%) of ABM in all stressed samples demonstrated that the principal peak was free from any co-eluting impurity or excipient peaks, as shown by parallel control and stressed placebo preparations. The samples and standard solutions were found to be stable for 36 hours at room temperature. Therefore, the method for ABM assay was found to be stability indicating, as shown by detailed results in Table I.

\section{Effect of heat on the degradation profile of $A B M$ in different solvents}

$\mathrm{ABM}$ solutions were stressed at 55 and $70{ }^{\circ} \mathrm{C}$ for 50 days and the results of periodic analysis were recorded as plots of concentration against time. A typical plot at $70{ }^{\circ} \mathrm{C}$ demonstrating the analysis results is presented in Fig. 2. The results showed a significant loss of ABM concentration with time, i.e., an increase in the concentration of degradation products (DPs) in all solvent preparations, except GF, where ABM showed relatively good stability. The noticeable loss in concentration observed for ABM in DMF (apparent $\mathrm{pH} \sim 9$ ) was similar to aqueous alkaline hydrolysis, where AVMs are known to degrade fast with the formation of the 2-epi isomer and $\triangle 2,3-\mathrm{ABM}$ isomer as major impurities (10). Degradation of ABM in EL and DGBE ( $\mathrm{pH} 3.0$ and 4.2 after stress at $70{ }^{\circ} \mathrm{C}$ ) was expected to follow the known acidic hydrolysis behavior, which leads to the formation of monosaccharide and aglycone in trace amounts (9). In contrast, irrespective of the marked loss of $\mathrm{ABM}$ concentration, there were no corresponding major impurity peaks 
A. Awasthi et al.: Evaluation of degradation kinetics for abamectin in formulations using a stability indicating method, Acta Pharm. 63 (2013) 59-69.

Table I. Method validation

\begin{tabular}{|c|c|c|}
\hline \multicolumn{2}{|l|}{ Validation parameters } & \multirow[t]{2}{*}{ Result } \\
\hline Test & $\begin{array}{l}\text { Concentration } \\
\left(\mu \mathrm{g} \mathrm{mL} \mathrm{mL}^{-1}\right)\end{array}$ & \\
\hline Linearity $\left(R^{2}\right)$ & $50-150$ & 0.9994 \\
\hline \multirow[t]{3}{*}{ Accuracy $(\% \text {, recovery })^{\mathrm{a}}$} & 50 & 99.5 \\
\hline & 100 & 98.6 \\
\hline & 150 & 99.3 \\
\hline \multirow[t]{3}{*}{ Method precision - intra-day $(\mathrm{RSD}, \%)^{\mathrm{a}}$} & 50 & 0.5 \\
\hline & 100 & 0.5 \\
\hline & 150 & 0.7 \\
\hline \multirow[t]{3}{*}{ Inter-day (RSD, \%) ${ }^{\mathrm{a}}$} & 50 & 0.7 \\
\hline & 100 & 1.0 \\
\hline & 150 & 1.2 \\
\hline
\end{tabular}

$R^{2}$ - coefficient of determination.

a $n=3$.

in the chromatograms of these two preparations. Thus indicates that impurities formed during such degradations were not UV absorbing and therefore degradation pathways under non-aqueous conditions did not resemble the typical acid hydrolysis of ABM. In addition, degradation behavior of ABM in DMF and EL was found to be non-linear at the end of the studies. This can be attributed to the change in degradation rate with time due to deviation in the medium $\mathrm{pH}$ as well as the presence of secondary degradents.

First-order degradation rate constant $\left(k_{\mathrm{obs}}\right)$ was calculated from the slope of logarithmic plots of drug concentration against time in days as shown in Fig. 2. The rate of $\mathrm{ABM}$ degradation in various solvents demonstrated the coefficient of determination $\left(R^{2}\right)$
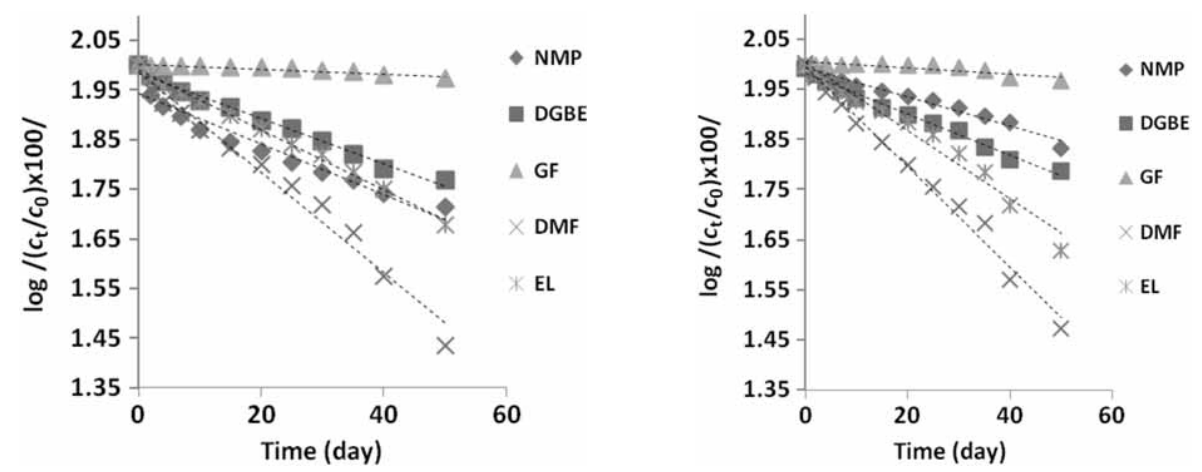

Fig. 2. First-order plots showing degradation of abamectin in abamectin/DMF formulation at $70^{\circ} \mathrm{C}$ in NMP, DGBE, GF, DMF, and EL: a) effect of heat, b) effect of heat and alkali. 
A. Awasthi et al.: Evaluation of degradation kinetics for abamectin in formulations using a stability indicating method, Acta Pharm. 63 (2013) 59-69.

Table II. Effect of heat $\mathrm{k}_{o b s}, \mathrm{R}^{2}$ and $\mathrm{t}_{1 / 2}$ of abamectin incubated in different solvents at 55 and $70{ }^{\circ} \mathrm{C}$

\begin{tabular}{lccccccc}
\hline Solvent & \multicolumn{3}{c}{$55^{\circ} \mathrm{C}$} \\
\cline { 2 - 8 } & Condition & $k_{\text {obs }}\left(\mathrm{s}^{-1}\right)$ & $R^{2}$ & $t_{1 / 2}$ (days) & $k_{\text {obs }}\left(s^{-1}\right)$ & $R^{2}$ & $t_{1 / 2}$ (days) \\
\hline NMP & Heat & 0.0037 & 0.9685 & 186.9616 & 0.0061 & 0.9908 & 114.2091 \\
& Heat + alkali & 0.0065 & 0.9368 & 107.2541 & 0.0133 & 0.9566 & 52.1917 \\
DGBE & Heat & 0.0056 & 0.9947 & 123.8828 & 0.0096 & 0.9927 & 72.1838 \\
& Heat + alkali & 0.0051 & 0.9912 & 135.1962 & 0.0109 & 0.9936 & 63.3437 \\
GF & Heat & 0.0002 & 0.7774 & 3831.346 & 0.0006 & 0.7711 & 1218.0672 \\
& Heat + alkali & 0.0003 & 0.8983 & 2175.7832 & 0.0008 & 0.9532 & 890.1262 \\
DMF & Heat & 0.0054 & 0.9899 & 128.3498 & 0.0207 & 0.9964 & 33.4074 \\
& Heat + alkali & 0.0068 & 0.9654 & 101.6656 & 0.0201 & 0.9930 & 34.5419 \\
EL & Heat & 0.0082 & 0.9975 & 84.3729 & 0.0130 & 0.9952 & 53.2500 \\
& Heat + alkali & 0.0067 & 0.9817 & 103.1546 & 0.0130 & 0.9939 & 53.5044 \\
\hline
\end{tabular}

NMP - N-methyl pyrrolidone, DGBE - diethyleneglycol monobutyl ether, GF - glycerol formal, DMF - dimethylformamide, EL - ethyl lactate

Table III. Activation energy $\left(\mathrm{E}_{a}\right)$ and frequency factor (A) for degradation of abamectin incubated in different solvents

\begin{tabular}{lcccc}
\hline Solvent & \multicolumn{2}{c}{$E_{\mathrm{a}}\left(\mathrm{kJ} \mathrm{mol}^{-1}\right)$} & \multicolumn{3}{c}{$A\left(\mathrm{~s}^{-1}\right)$} \\
\cline { 2 - 5 } & Heat & Heat and alkali & Heat & Heat and alkali \\
\hline NMP & 7.353 & 10.746 & 19.330 & 28.247 \\
DGBE & 8.058 & 11.311 & 21.181 & 29.734 \\
GF & 17.097 & 13.334 & 44.951 & 35.059 \\
DMF & 20.081 & 16.105 & 52.792 & 42.338 \\
EL & 6.867 & 9.7948 & 18.045 & 25.744 \\
\hline
\end{tabular}

NMP - N-methyl pyrrolidone, DGBE - diethyleneglycol monobutyl ether,

GF - glycerol formal, DMF - dimethylformamide, EL - ethyl lactate

values $>0.95$, except for GF, which were inconclusive since the small variations in assays were likely due to analytical variations rather than degradation. A comparison of the degradation rate constant $k_{\mathrm{obs}}\left(\mathrm{s}^{-1}\right)$ and half-life $\left(t_{1 / 2}\right.$ (days)) of ABM in various solvents shows that the degradation rate in EL was higher than in other solvents (rate constant $0.0082 \mathrm{~s}^{-1}$, and half-life 84 days), while GF preparation showed the lowest degradation. However, the increase in temperature from 55 to $70{ }^{\circ} \mathrm{C}$ caused a marked increase in degradation rate and reduction in half-life. DMF was found to be more actively degrading $\mathrm{ABM}$ at $70{ }^{\circ} \mathrm{C}$ (rate constant $0.0207 \mathrm{~s}^{-1}$, half-life 33.4 days). GF showed a significant drop in half-life at $70{ }^{\circ} \mathrm{C}$, but the changes can still be considered insignificant since the results showed a half-life of 1218 days. Apart from GF, ABM was found to be relatively more stable in NMP under both storage conditions (half-life 187 and 114 days). The effects of heat on the coefficient of determination, slope and rate constant values for ABM degra- 
A. Awasthi et al.: Evaluation of degradation kinetics for abamectin in formulations using a stability indicating method, Acta Pharm. 63 (2013) 59-69.

dation in various solvents are shown in Table II. The activation energy $\left(E_{\mathrm{a}}\right)$ and frequency factor $(A)$ for solvents used in the stress studies were also calculated and are shown in Table III.

\section{Effect of alkali on the degradation profile of $A B M$ in different solvents}

The stress study of ABM solutions spiked with known amounts of alkali solution was carried out and a typical plot at $70{ }^{\circ} \mathrm{C}$ presented in Fig. 2. It demonstrated a significant change in $\mathrm{ABM}$ concentration for all solvent preparations except GF, where ABM showed good stability. Comparison of these results with the experiments in the absence of alkali showed that addition of alkali resulted in greater loss of ABM concentration in NMP and DMF preparations. In contrast, for DGBE and EL preparations, it resulted in
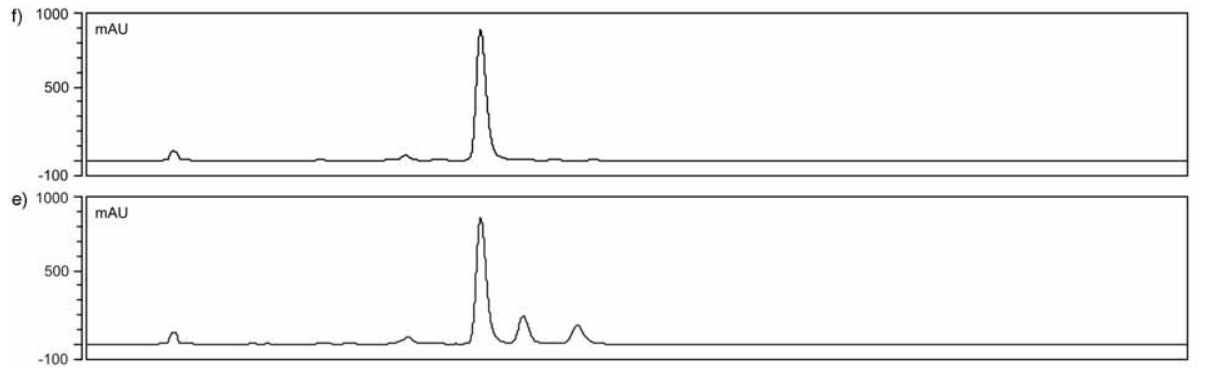

d)

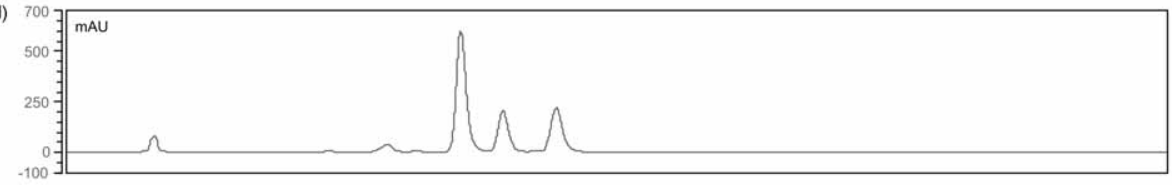

c)

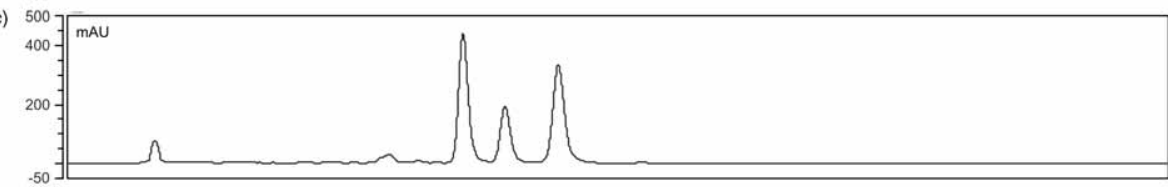

b)

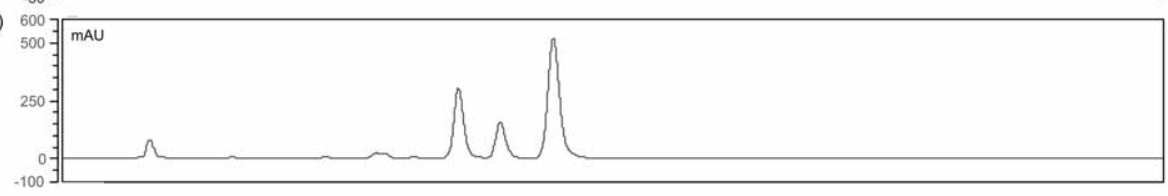

a)

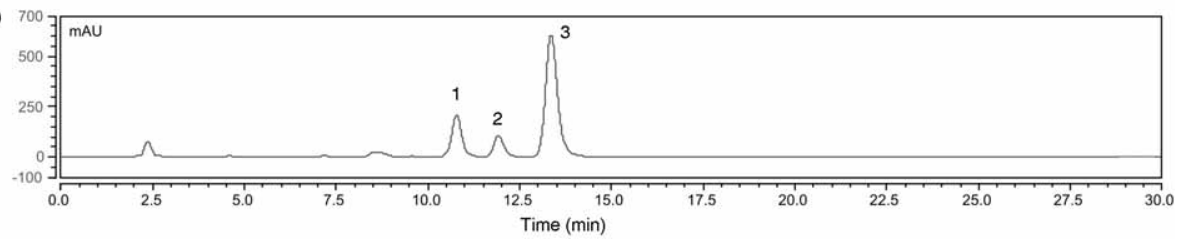

Fig. 3. HPLC chromatogram of abamectin in a) abamectin/DMF formulation showing the effect of heat $\left(70^{\circ} \mathrm{C}\right)+$ alkali, a) day 50, b) day 40, c) day 30, d) day 20, e) day 10 and f) day-0 chromatograms. The labels on a typical chromatogram represent the peaks of: abamectin B1a (1), 2-epi-abamectin (2) and C) $\Delta 2,3$-abamectin (3). 


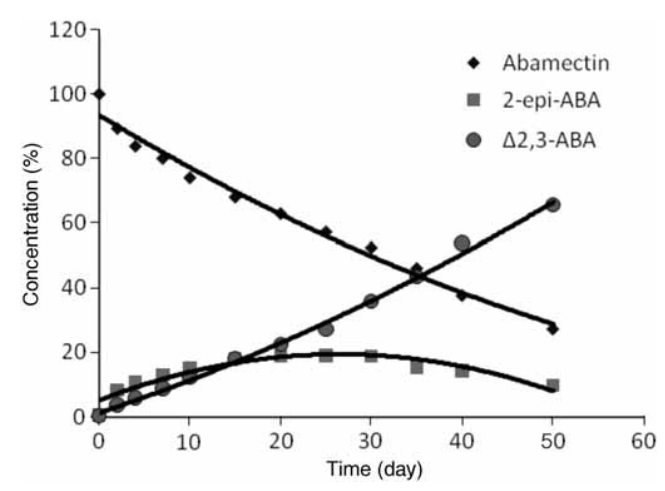

Fig. 4. Degradation profile of abamectin in the abamectin+DMF formulation at $70{ }^{\circ} \mathrm{C}$ (alkali).

slight improvements in assays compared to the absence of alkali treatment. In addition, GF preparations were not adversely affected by alkali addition. Typical chromatograms of stress study samples of ABM in DMF of various days at $70{ }^{\circ} \mathrm{C}$ are shown in Fig. 3.

We have recently demonstrated that stressing of $\mathrm{ABM}$ or its derivative eprinomectin in DMF produced DPs characteristics of alkaline conditions, i.e., 2-epi- and $\Delta 2,3-\mathrm{AVMs}$ $(11,12)$. The characterization results, which are directly related to stress studies discussed in this work, showed that, in addition to the prompt formation of the 2-epimer in an alkaline solution, whether an alkali or apparently alkaline organic solvents (e.g., amide solvents), the $\Delta 2,3$-isomer was produced with a concurrent decline in the concentration of both AVM, and its 2-epi-isomer (11). Given that these DPs typically lack the powerful anthelmintic activity of AVM, it is very important to thoroughly understand the stability profile of $\mathrm{ABM}$ in the proposed representative solvents because so far no such discussion has been reported for formulations (10).

Interestingly, the degradation of ABM in NMP and DMF shows a slightly lower coefficient of determination value ( 0.95) in comparison with other solvents, possibly due to the slight change in ABM degradation pathways in the latter half of the studies. The ABM degradation in NMP and DMF clearly showed first-order kinetics at the beginning of the experiment, but after 15 days, a change in the apparent $\mathrm{pH}$ of solutions and formation of secondary DPs presumably altered the degradation kinetics. Fig. 4 shows the plot for $\mathrm{ABM}$ concentrations and impurities, probably 2-epi- and $\triangle 2,3-\mathrm{ABM}$, changing with time at $70{ }^{\circ} \mathrm{C}$ in DMF spiked with alkali. The plot showed that the concentration of 2-epi-ABM reached a maximum after 20 days followed by a gradual decline. On the other hand, the $\triangle 2,3-\mathrm{ABM}$ concentration increased steadily over time. The data in Table II shows the effect of alkali and heat on the coefficient of determination, slope and rate constant values for ABM stability in various solvents. The rate of ABM degradation and half-life at 55 and $70{ }^{\circ} \mathrm{C}$ were adversely affected for some solvents and the changes are more noticeable at $55^{\circ} \mathrm{C}$ is the samples reached equilibrium at $70{ }^{\circ} \mathrm{C}$. Addition of alkali to a sample under heat stress acted on ABM depending upon the properties of the solvents in formulation. For amide solvents such as NMP and DMF, it increased the rate of reaction (for NMP rate constant from $0.0037 \mathrm{~s}^{-1}$ to $0.0065 \mathrm{~s}^{-1}$ ) and decreased the shelf life (for NMP, half-life from 187 to 107 days). On the other hand, addition of alkali into sol- 
vents known to be acidic such as EL resulted in an increase of shelf life $\left(t_{1 / 2}\right.$ from 84 to 103 days) since the added alkali slightly neutralized the formulation and thus provided a stabilization effect for ABM. This demonstrates that the alkaline component in the formula typically causes degradation. However, in some cases it is controlled by the chemical properties of the formulation medium as well. The activation energy $\left(E_{\mathrm{a}}\right)$ and frequency factor $(A)$ for solvents used in the stress study with alkali were also calculated and are shown in Table III.

\section{Physical appearance}

During the stress studies, a significant color change from the initial colorless liquid to a light-yellow liquid was noticed in NMP and DMF preparations. This may be associated with the degradation of ABM into various impurities, including the 2-epi- isomer and $\Delta 2,3$-isomer. The color of other preparations was unaffected by the stress conditions.

\section{pH effect}

The measurement of $\mathrm{pH}$ demonstrated that the ABM preparations in amide based solvents like NMP ( $\mathrm{pH}$ 9.9) and DMF ( $\mathrm{pH}$ 9.6) which are alkaline in nature, produced the same degradation impurities as those observed in earlier work in alkali (10). Addition of alkali to these two samples resulted in an increase in $\mathrm{pH}$ to 11.1 and 12.1, respectively; however, storage of samples at elevated temperature for 50 days reduced the $\mathrm{pH}$ by three units with alkali and two units without alkali spiking for both solvents. In comparison, GF ( $\mathrm{pH}$ 6.1) and DGBE ( $\mathrm{pH}$ 6.5) were found to be near neutral, while EL was found to be slightly acidic ( $\mathrm{pH} 4.7$ ). Stressing the samples at 55 and $70{ }^{\circ} \mathrm{C}$ resulted in further reduction in $\mathrm{pH}$ which is less pronounced in GF ( $\mathrm{pH} 5.8$ and 4.8), while more acidic for EL ( $\mathrm{pH} 3.2$ and 3.0) and DGBE ( $\mathrm{pH} 5.1$ and 4.8). Interestingly, addition of alkali to these solvent has retarded the $\mathrm{pH}$ reduction to some extent, which is reflected in a slight improvement of ABM stability compared to unspiked samples. These observations clearly emphasize that the stability of $\mathrm{ABM}$ is also greatly influenced by the inherent $\mathrm{pH}$ of solvents in addition to alkali.

\section{CONCLUSIONS}

ABM preparations in non-aqueous solvents were evaluated for stability and the results showed a decrease in ABM concentration under the influence of heat and alkali. Kinetic evaluation data indicates that $\mathrm{ABM}$ degradation follows first-order kinetics; however, the loss rate, i.e., $k_{\mathrm{obs}}$ value greatly varies from solvent to solvent and is distinct from known hydrolysis. ABM preparation in GF was found to be the most stable. Since this is a first study on ABM stability behavior in multiple non-aqueous solvents, it will serve as a platform to develop shelf-life stable ABM products.

Acknowledgements. - This research work was kindly supported by Technology New Zealand (TechNZ) and Ancare Scientific Ltd, New Zealand. The authors thank Prof. Saranjit Singh (NIPER, India) and Mr. Robert Holmes for their thoughtful discussions and advice. 
A. Awasthi et al.: Evaluation of degradation kinetics for abamectin in formulations using a stability indicating method, Acta Pharm. 63 (2013) 59-69.

\section{REFERENCES}

1. J. R. Egerton, D. A. Ostlind and L. S. Blair, Avermectins, new family of potent anthelmintic agents: Efficacy of the Bla component, Antimicrob. Agents Chem. 15 (1979) 372-378; DOI: 10.1128/aac. 15.3.372.

2. E. A. Ottesen and W. C. Campbell, Ivermectin in human medicine, J. Antimicrob. Chemoth. 34 (1994) 195-203; DOI: 10.1093/jac/34.2.195.

3. V. Manetta and G. R. Watkins, Topical Formulation of Ivermectin for the Treatment of Dermatological Conditions, WO 2004093886; ref. Chem. Abstr. 141 (2004) 384319.

4. W. L. Shoop, H. Mrozik and M. H. Fisher, Structure and activity of avermectins and milbemycins in animal health, Vet. Parasitol. 59 (1995) 139-156; DOI: 10.1016/0304-4017(94)00743-V.

5. R. W. Burg, B. M. Miller and E. E. Baker, Avermectins, new family of potent anthelmintic agents: Producing organism and fermentation, Antimicrob. Agents Ch. 15 (1979) 361-367; DOI: 10.1128/ AAC.15.3.361.

6. M. J. Gliddon, Stabilized Formulations Comprising Moxidectin, Australian Pat. AU 2006100657 A4; ref. Chem. Abstr. 146 (2006) 107451.

7. United States Pharmacoepia 33, National Formulary 28, USP Convention, Rockville (MD) 2010.

8. D. W. Fink, Ivermectin, in Analytical Profiles of Drug Substances (Ed. F. Klaus), Academic Press, New York 1988, pp. 155-184; DOI: 10.1016/S0099-5428(08)60219-1.

9. W. Shoop, Ivermectin, Abamectin and Eprinomectin, in Macrocyclic Lactones in Antiparasitic Therapy (Eds. J. Vercruysse and R. S. Rew), CABI Publishing, Wallingford 2002, pp. 1-11; DOI: 10.1079/ 9780851996172.0000 .

10. J. V. Pivnichny, B. H. Arisen, F. A. Preiser, J. S. K. Shim and H. Mrozik, Base-catalyzed isomerization of avermectins, J. Agr. Food Chem. 36 (1988) 826-828; DOI: 10.1021/jf00082a039.

11. A. Awasthi, M. Razzak, R. Al-Kassas, D. R. Greenwood, J. Harvey and S. Garg, Separation and identification of degradation products in eprinomectin formulation using LC, LTQ FT-MS, H/D exchange and NMR, J. Pharm. Biomed. Anal. 63 (2012) 62-73; DOI: 10.1016/j.jpba.2011.12.030.

12. A. Awasthi, M. Razzak, R. Al-Kassas, D. R. Greenwood, J. Harvey and S. Garg, Separation and identification of degradation products in abamectin formulation using LC, LTQ FT-MS, H/D exchange and NMR, Curr. Pharm. Anal. (2012), In press.

13. J. D. Stong, J. V. Pivnichny, H. Mrozik and F. S. Waksmunski, Radical-induced oxidation of oxahydrindene (hexahydrobenzofuran) portion of 22,23-dihydroavermectin B(1a): Identification of autooxidation products, J. Pharm. Sci. 81 (1992) 1000-1003; DOI: 10.1002/jps.2600811008.

14. M. S. Maynard and H. D. Maynard, HPLC assay for avermectin Bla and its two photoisomers using a photo diode array detector, Bull. Environ. Contam. Toxicol. 43 (1989) 499-504; DOI: 10.1007/ BF01701926.

15. L. S. Crouch, W. F. Feely, B. H. Arison, W. J. A. VandenHeuvel, L. F. Colwell, R. A. Stearns, W. F. Kline and P. G. Wislocki, Photodegradation of avermectin B1a thin films on glass, J. Agr. Food Chem. 39 (1991) 1310-1319; DOI: 10.1021/jf00007a024.

16. A. Awasthi, M. Razzak, R. Al-Kassas, J. Harvey and S. Garg, An overview on chemical derivatization and stability aspects of selected avermectin derivatives, Chem. Pharm. Bull. 60 (2012) 1-14.

17. R. Schmidt, Effect of Solvent on Chemical Reactions and Reactivity, in Handbook of Solvents (Ed. G. Wypych), ChemTec Publishing, Toronto 2001, pp. 737-846.

18. International Conference on Harmonisation of Technical Requirements for Registration of Veterinary Medicinal Products. VICH GL-2, Validation of Analytical Procedures: Methodology, Brussels 1998; http:/ / www.vichsec.org/en/topics.htm\#1, last access September 17, 2012.

19. S. F. Martin, How to measure $\mathrm{pH}$ in mixed and nonaqueous solutions, Today's Chemist at Work 6 (1995) pp. 39-42. 